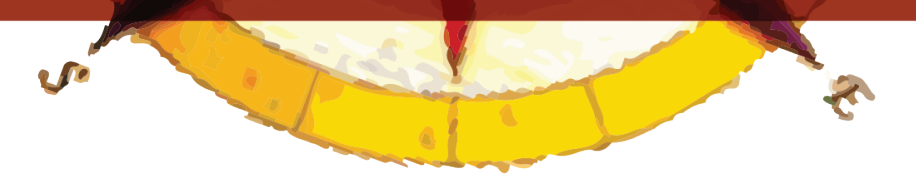

\title{
LA EDUCACIÓN GEOGRÁFICA EN CHILE: DESDE SU APARICIÓN EN EL CURRÍCULUM ESCOLAR EN EL SIGLO XIX HASTA LOS AJUSTES CURRICULARES DE 2010
}

\author{
Paloma Miranda Arredondo ${ }^{1}$
}

\section{RESUMEN}

En este artículo, se expone un análisis del currículum de Geografía desde su incorporación al sistema educativo formal (a fines del período colonial) hasta la actualidad, relacionando su presencia y orientación curricular con los diferentes modelos epistemológicos observados en el desarrollo histórico de la Geografía.

Metodológicamente, se realiza un análisis documental a los currículos escolares, tanto de educación básica como de educación media, desde 1809 hasta la actualidad. A partir de ello, se visualizan tres momentos: una educación geográfica pre moderna, una Geografía escolar subsidiaria de la Historia, y una Geografía como parte de los estudios sociales. Así, las modificaciones al currículum de Geografía se explican más por la conformación de la identidad de los ciudadanos, que por los avances teóricos y metodológicos de la Geografía como ciencia.

Palabras claves: Currículum de Geografía, Análisis Histórico del Curriculum, Paradigmas de la Educación Geográfica.

\section{ABSTRACT}

The present article exposes an analysis to the Geography curriculum that dates back from its incorporation to the formal educational system (by the end of the colonial period) to the present time by relating its curricular appearance and orientation to the different epistemological models that have been observed in the historical development of Geography.

In terms of methodology, a subject analysis of the school curricula including both primary and secondary schools' dating from 1809 to the present was carried out. From that analysis, three different periods were observed: a premodern Geography education, a school Geography supplementing History, and Geography as part of social studies. Thus, the modifications done to the Geography 
curriculum can be better explained by the formation of the citizen's identity than by the theoretical and methodological advances in Geography as a science.

Key words: Geography curriculum, Historical Analysis of the Curriculum, Paradigms in Geographic Education.

\section{INTRODUCCIÓN.}

La mayor parte de los autores dedicados a la investigación en educación geográfica en Chile consideran que la Geografía sólo aparece formalmente en el sistema educativo chileno con la fundación del Instituto Pedagógico en 1889. No obstante, es posible observar su presencia en el currículum escolar desde fines del período colonial. Ya en 1809 se dictaba cátedra de Geografía en la Academia de San Luis, la cual siguió apareciendo esporádicamente, según las experticias del profesorado disponible, en el Instituto Nacional hasta 1813, año en el que fue cerrado, tras la Reconquista Española.

Así, la educación geográfica ha estado presente en el currículum desde los comienzos del período republicano hasta la actualidad, con períodos de gran dinamismo y otros de estancamiento teórico. De acuerdo a lo anterior, el artículo analiza el currículum de Geografía desde su incorporación al sistema educativo, relacionando su presencia y orientación curricular con los diferentes modelos epistemológicos observados en su historia. Se incluye además en el análisis, las relaciones que dichas orientaciones y modelos han tenido con las etapas del desarrollo histórico del Estado nación. Para ello, el artículo se divide en tres apartados.

En primer lugar, se exponen los resultados del análisis del currículum de Geografía del siglo XIX. Este período denominado de la "Geografía autónoma", se caracterizó por desarrollar una Geografía escolar poco diferenciada de la Geografía académica, cuyo fin era describir la superficie terrestre. En esta etapa pre científica o descriptiva, la Geografía escolar es una disciplina independiente, pero se encuentra mucho más cercana a la matemática y cosmografía que a las humanidades.

Posteriormente, se analiza el currículum de Geografía elaborado tras la Promulgación de la Segunda Ley de Instrucción Primaria en 1920. En este período, la llamada "Geografía subsidiaria" se caracterizó por dos aspectos relevantes: en primer lugar, es incorporada a la educación primaria, dada su relevancia para la consolidación de la identidad nacional; en segundo lugar, es incluida en los estudios sociales, haciéndose subsidiaria de la Historia, dada la relevancia de ambas para la consolidación del Estado nación bajo el ideal de patriotismo. Es la Geografía científica positivista la que dominará el currículum durante todo el siglo XX, y cuya herencia se mantiene viva.

Por último, se presenta el análisis de la Geografía actual, tras la publicación de ajustes curriculares en 2010. Esta Geografía entendida de forma integrada, bajo un modelo sistémico, avanza en el diálogo y polifonía de las Ciencias Sociales, aunque sigue en lucha con las herencias del período anterior. Al finalizar, se exponen conclusiones, planteando que la Geografía es una disciplina casi tan antigua como el sistema educativo, y que las modificaciones a su currículum se han visto más influenciadas por la consolidación del Estado Nación, que por los avances teóricos y metodológicos de la Geografía misma como ciencia. 
La educación geográfica en el siglo XIX: La geografía como disciplina escolar descriptiva y autónoma.

A pesar de que algunos investigadores de la educación geográfica en Chile sitúan la aparición de la Geografía en el currículum recién en 1889 (Araya, 2009), año en que se funda el Instituto Pedagógico (institución formadora de profesores para la educación secundaria), ya en 1809 se observa la primera cátedra de Geografía en una institución educativa (Pereira, 1947). Al finalizar la colonia, Chile contaba sólo con escuelas de primeras letras, que enseñaban a leer, escribir y contar, y algunos convictorios y seminarios que ofrecían educación secundaria. Esto se explica por cuanto en el período colonial se necesitaban súbditos a la corona española y a la religión católica, por lo que el currículum escolar sólo buscaba acercamientos a las sagradas escrituras, elemento de unidad identitaria. No obstante, una vez en curso el proceso independentista y la idea del Estado nación, era necesario construir un nuevo referente identitario capaz de unir a la floreciente sociedad chilena, y tal como sucedió en todos los Estados en construcción, americanos y europeos, esto se realizó a través de la educación.

Por una parte, si bien se mantuvieron las escuelas de primeras letras hasta bien adentrado el siglo XIX, su currículum se amplió hasta incluir las cuatro operaciones matemáticas básicas, gramática, religión, doctrina cristiana y derecho del hombre. Por otro lado, se institucionalizó la educación secundaria, antes centralizada en la Academia de San Luis, luego consolidada en el Instituto Nacional y otros establecimientos como Liceo de Chile y Colegio de Santiago. Lo anterior se observa en la Cartilla de Educación: observaciones sobre la enseñanza científica y sobre el régimen de los colegios, publicada en diario El Mercurio del 12 de marzo de 1828:

"La vieja armazón de las monarquías se desmorona, y en su lugar se eleva el hermoso edificio de la patria, y de esta gran transformación emanan derechos y obligaciones que abrazan a todos los ciudadanos, y que exigen de ellos cualidades harto diferentes de las del vasallo, dócil a la voz absoluta de su dueño" (El Mercurio Chileno. Primer Número. 12de marzo de 1828, p.34)

En este contexto, la primera cátedra de Geografía en una institución escolar se dio en la Academia de San Luis, introducida en el programa de estudios secundarios por el Fray José María de Bazaguchiascúa (Pereira, 1947) quien dictó la cátedra de forma intermitente hasta que la Academia de San Luis se fusionó con el Convictorio Carolingio para fundar el Instituto Nacional en 1813. Bazaguchiascúa, incluso escribió una carta al gobernante José Miguel Carrera, para que la Geografía fuera incluida de forma permanente y sistemática en los estudios secundarios, y de grado universi$\operatorname{tario}^{2:}$

"Yo bien sé, que Vuestra Excelencia, un año ha, consulta los medios, y modos más oportunos, a exigir el Altar, desde donde esta juiciosa divinidad, de sus oráculos, y reina nuestros inciensos. No dificultó el buen éxito, a pesar de que los obstáculos no son pocos, fiado en que una buena intención, del mancomún con el deseo eficaz todo lo vence. Mas si esta deidad la constituyen los atributos como son las ciencias Lógicas, Matemáticas, Física, Ética, Medicina: Teología Positiva Escolástica, Dogmática, Polémica, Expositiva, Moral; Ascética: Derecho Civil, Canónico y de Gentes: Aritmética, Geometría, Astronomía y Cosmografía, perfeccionándolos al mismo tiempo la historia de los Imperios, los reglamentos de una crítica refinada, el conocimiento de la antigüedad y la cronología de

2 Bazaguchiascúa, J. (1813) Memoria que manifiesta la necesidad de abrir grados e instituir cátedra de geografía en la Real Universidad de esta ciudad". 
los siglos; la Geografía Sagrada y Profana sobre ser la base y sustentáculo sin cuya firmeza, no puede asegurarse su duradera estabilidad, son como unos perfiles que completan su hermosura, como unos esmaltes que realzan su belleza, o como la corona que ciñe gallardamente las sienes de esta Deidad. Sí señor, porque sin los estudios de esta ciencia, se trabaja en las otras, la mayor parte infructuosamente". (Bazaguchiascúa, 1813: 2)

Los argumentos de Bazaguchiascúa se fundaban básicamente en la emergencia del Estado moderno y de la apertura comercial de las nacientes repúblicas americanas. También fundaba la incorporación de la Geografía a la educación secundaria y universitaria, en la necesidad de los miembros de la elite, de conocer con detalle la superficie terrestre.

\begin{abstract}
"No podemos negar la importancia de la Geografía para todo ciudadano; pero en especial para los Ministros de Estado, asciende muy alto esta necesidad (...) Mas si es de gran necesidad esta ciencia, a los Ministros de Estado, otro tanto más lo es para los de Guerra y sus Generales (...) Así es que están llenas las historias, de buenos o malos sucesos de armas por haberse valido o despreciado los conocimiento de la Topografía. Y si en él que comanda las tropas es tan indispensable esta instrucción, no es lo menos en quien haya de historiar estas acciones, pues este viene a ser eco de aquella voz". (Bazaguchiascúa, 1813: 3)
\end{abstract}

Si bien los intentos de Bazaguchiascúa fueron intensos, la Geografía sólo llegó al nivel superior al fundarse la Universidad de Chile en 1842, y la carrera de ingeniería geográfica de la Facultad de Matemática y Física. La Licenciatura en Geografía por su parte, llegó a la universidad en la década de 1970 (Santis, 1981). No obstante, su inclusión a los estudios secundarios fue paralelo al nacimiento del Estado chileno, a través de las escuelas preparatorias para la universidad.

\begin{abstract}
"Pensar con exactitud y hablar con claridad y elegancia, son condiciones tan necesarias al abogado como al militar, al legislador como al economista. Unos y otros no perderán nada en el conocimiento del globo que habitan, en el de la historia de los grandes pueblos, cuyos idiomas y leyes hemos heredado, en la adquisición de las teorías que determinan la formación de la riqueza, por último, en la iniciación de los grandes misterios de la naturaleza (...) Las humanidades, las matemáticas puras, la ideología, la geografía, la historia, la economía política, y la química abrazan todo este círculo, al cual, en nuestro sentir, debe limitarse la educación preparatoria en estos países" (E1 Mercurio Chileno, Primer número, 12 de marzo de 1828, pág. 35)
\end{abstract}

Así, las cátedras de Geografía en educación secundaria fueron permanentes en el Instituto Nacional desde 1813, como en la mayor parte de los liceos del país, a través del plan de humanidades, que incluía a la Geografía en primer y sexto año de humanidades con asignaturas de Geografía descriptiva y física respectivamente, las que contaban con 3 horas semanales. El plan de estudios del Instituto Nacional sirvió de modelo para la elaboración de los planes de estudio del resto de los liceos, públicos y privados. El Liceo de Chile fundado en 1828, y el Colegio de Santiago fundado por la Sociedad Chapsuis en 1829, incorporaban en sus programas, Geografía matemática, heredera de las nociones de cosmografía y Geografía general o descriptiva3.

3 El programa del Liceo de Chile, fundado en 1828, por José Joaquín de Mora, fue publicado in extenso en: E1 Mercurio de Valparaíso, Nº 33, del 17 de diciembre de 1828, pág. 129-130. 
A pesar de que Geografía escolar y Estado nación coinciden en su origen, el paradigma que sostiene a la Geografía en el nivel secundario durante el siglo XIX es el ideario ilustrado, y no la idea de espacio vital de Ratzel, y de la Geografía positivista que sustentó el surgimiento de varios estados europeos a fines del siglo. Esto explica que la Geografía haya sido considerada sólo en educación secundaria, a la que solo accedían las elites hasta inicios del siglo XX y cuyo fin, junto al de otras áreas del conocimiento, como planteaba Barrenechea (1913: 91) era formar a un determinado tipo de ser humano, con dominio de "idiomas a los que llame su inclinación (...) criterio en la lógica y corazón en la ética y religión; que verá el mundo en la geografía; y entretendrá a gusto en historia y bellas letras, para situarlas en las mismas cátedras".

Es por esto que los contenidos de Geografía correspondían en este período a lo que actualmente denominamos Geografía general, y eran estudiados a través de textos traídos desde Europa, especialmente Francia4, a la vez que se hacían indispensables los mapas del mundo y globos terráqueos. Los contenidos de la asignatura denominada Geografía descriptiva contenían lecciones elementales de cosmografía, Geografía general y política, que estudiaban la conformación del globo terráqueo, descripción de los continentes y las tierras polares. Por una parte, se incluía la división natural del globo y por otra, la división política de la Tierra que consideraba la división de Europa, con especial consideración de la descripción de España y, en menor medida la descripción de Asia, África, América, y de las Tierras Polares5.

Los profesores de Geografía no eran muchos, y generalmente eran de otras asignaturas, y desarrollaban la cátedra de Geografía por su bagaje cultural y conocimiento del mundo derivado de sus viajes, tal era el caso José María Bazaguchiscúa, Manuel J. Villalón, José V. Lastarria y Gonzalo Cruz (Ávila, 1982). En este sentido, fue fundamental la conformación de la Sociedad Chapsuis y la fundación por parte de esta sociedad del Colegio de Santiago, que trajo a expertos franceses de renombre para dictar la cátedra, como Claudio Gay, Théodore Morinière y Verdollín. La Geografía encontraba presencia en la enseñanza elemental y de humanidades y se dividía en dos secciones: una en la que los estudiantes se dedicaban al estudio de los aspectos físicos y descriptivos del mundo y otra constituida por Cosmografía, Geografía política y Geografía descriptiva e histórica. También se realizaban ejercicios de dibujos de mapas de una hora cronológica, dos veces a la semana (Chapsuis, 1828)6

\footnotetext{
"Siendo absolutamente necesario el conocimiento de la esfera para estudiar con fruto la geografía, se dará principio a este curso por un bosquejo del sistema general del mundo esferas (...) Este bosquejo terminará con la explicación de los fenómenos que resultan del movimiento de los cuerpos celestes. El estudio de la geografía no se reducirá a estadística; se estudiarán además, las costumbres,
}

4 Algunos textos franceses que se utilizaban para la enseñanza de la geografía eran: "Elementos de geografía" traducido de la obra titulada "Enseñanza Universal", en 1846 y de autoría anónima; "Cosmografía y geografía física" de E. Cortambert (1850); "Elementos de geografía física" de E. Corambert (1867) y; "Elementos de cosmografía" de A. Guillermín (1869).

5 Una muestra de los contenidos de geografía descriptiva y, de su organización para la enseñanza se puede observar en el Compendio geográfico escrito por el Doctor don Juan Pablo Fretes en 1813. Este compendio fue publicado en su versión original bajo el título de: "Compendio Geográfico escrito por el Doctor don Juan Pablo Fretes, Racionero de la Yglecia Cathedral de Santiago de Chile, para uso de la Juventud Americana", en la Revista de Geografía Norte Grande, № 17, 1990.

Acta de sociedad para la fundación de una universidad en Chile. El Señor Domingo Lambert, notario de París, 11 de abril de 1828 . 
los usos, la religión y la política de los diferentes lugares que se describan, lo que dará origen a la división de este estudio en geografía física, moral y, política. Se demostrará también la confección de cartas marítimas, conservando las más exactas en la sala de estudio con nombre de sus autores" (Chapsuis, 1828:2).

Si bien, el primer currículum oficial chileno se publicó en 1843, hubo un primer intento en 1832, el Proyecto de Plan de Estudios formado por la Comisión Encargada por el Supremo Gobierno, llamada "De la enseñanza secundaria y de la profesional y científica"7. E1 proyecto proponía dividir la educación secundaría en dos secciones: enseñanza preparatoria o secundaria, y enseñanza profesional o científica.

Junto con ello se establecía que la enseñanza secundaria comprendía entre otras asignaturas, Geografía moderna y antigua, la cual se conformaba como una clase subalterna8. Siguiendo como modelo el proyecto de 1832, se elaboró el Plan de Estudios Humanistas en 1843. Para la Geografía, el plan de estudios significó sólo un cambio de nivel, ya que pasó de ser una actividad curricular del primer año de humanidades, al segundo año (Cruz, 1967). Sin embargo, tal disposición no fue duradera, ya que al observar el plan de estudios de los liceos de Chile antes de la implantación del sistema concéntrico (Labarca, 1948) la Geografía vuelve a aparecer en primer año (Geografía descriptiva) y en sexto año de humanidades (Geografía física). De este modo, la Geografía estuvo presente en el currículum escolar de nivel secundario, sin grandes cambios durante el siglo XIX. Sin embargo, con el Plan de Estudios Concéntricos en 1889, se realizó uno de los cambios más significativos y duraderos. La Geografía, descriptiva y autónoma característica del período se unió a los estudios históricos en la asignatura denominada Historia y Geografía, presente en todos los niveles de la educación secundaria, de primero a sexto año de humanidades, con tres horas semanales los cuatro primeros años y cuatro horas en los dos últimos (Labarca, 1927).

Así entonces, y tomando como referencia los programas de estudio tanto de la Academia de San Luis (1809) como del Instituto Nacional (1813/1819/1832), el Liceo de Chile (1828) y el Colegio de Santiago (1829); el plan humanista de estudios secundarios; implementados en las escuelas secundarias o preparatorias de carácter público entre 1819 y 1843; hasta la implementación efectiva del plan de estudios concéntricos de 1889. Se puede decir que, la Geografía escolar, correspondía esencialmente a una Geografía descriptiva, de carácter generalista que presentaba pocas diferencias con la Geografía académica que tradicionalmente se desarrollaba en las universidades. La Geografía escolar de este período, respondía al paradigma clásico o pre científico, cuya finalidad era describir, con altos niveles de detalle, la superficie de la Tierra permitiendo ampliar los niveles de conocimiento anhelados por el ideal ilustrado consolidado y dirigente en dicho período.

$7 \quad$ Publicado en El Araucano, No 69, Santiago, 07 de enero de 1832.

8 El plan de estudios denominado "De la enseñanza secundaria y de la profesional y científica" establecía para el Instituto Nacional (modelo para los demás establecimientos del país) tres tipos de clases: principales, subalternas y, accesorias. 


\begin{tabular}{|c|c|c|c|c|c|c|}
\hline$\underline{\text { Período }}$ & Extensión & $\frac{\text { Posición }}{\text { curricular }}$ & $\begin{array}{l}\text { Objetivo } \\
\text { educativo }\end{array}$ & $\frac{\text { Contenidos }}{\underline{\text { disciplinares }}}$ & $\frac{\text { Disciplinas }}{\underline{\text { afines }}}$ & $\frac{\text { Modelo }}{\text { epistemológico }}$ \\
\hline $\begin{array}{l}\text { Geografía } \\
\text { autónoma }\end{array}$ & $\begin{array}{l}\text { Desde la } \\
\text { formalización } \\
\text { de las cátedras } \\
\text { de geografía en } \\
\text { la educación } \\
\text { secundaria en } \\
\text { la Academia } \\
\text { de San Luis } \\
\text { (1809) hasta } \\
\text { la unión de la } \\
\text { geografía y la } \\
\text { historia como } \\
\text { asignatura } \\
\text { del plan de } \\
\text { estudios } \\
\text { concéntricos } \\
\text { (1889) }\end{array}$ & $\begin{array}{l}\text {-Nivel } \\
\text { secundario } \\
\text {-Primer y } \\
\text { sexto año de } \\
\text { humanidades }\end{array}$ & $\begin{array}{l}\text { Conocer y } \\
\text { describir la } \\
\text { superficie } \\
\text { de la } \\
\text { Tierra. }\end{array}$ & $\begin{array}{l}\text {-Geografía } \\
\text { descriptiva } \\
\text { o general: } \\
\text { Conformación } \\
\text { del globo } \\
\text { terráqueo, } \\
\text { descripción de } \\
\text { los continentes } \\
\text { y tierras polares } \\
\text {-Geografía } \\
\text { política: } \\
\text { División } \\
\text { de Europa, } \\
\text { con especial } \\
\text { consideración } \\
\text { de la } \\
\text { descripción de } \\
\text { España, y en } \\
\text { menor medida } \\
\text { de Asia, África, } \\
\text { América y las } \\
\text { Tierras Polares }\end{array}$ & $\begin{array}{l}\text { Matemática, } \\
\text { Física y } \\
\text { Cosmografía }\end{array}$ & $\begin{array}{l}\text { Geografía } \\
\text { descriptiva o pre- } \\
\text { científica }\end{array}$ \\
\hline
\end{tabular}

Figura $\mathrm{N}^{\mathrm{o}}$ 1: Características de la geografía escolar durante el siglo XIX Fuente: Elaboración propia.

\section{LA EDUCACIÓN GEOGRÁFICA EN EL SIGLO XX: POSITIVISMO Y SUBORDINACIÓN A LOS ESTUDIOS HISTÓRICOS.}

El plan de estudios concéntricos de 1889 significó un gran cambio para la Geografía escolar. Si bien ya se veían transformaciones en la Geografía con la Primera Ley de Instrucción Primaria de 1860, que incluyó a la disciplina en la educación elemental y que avanzó hacia una Geografía del territorio nacional, el plan consolidó un cambio teórico respecto de la disciplina. La Geografía descriptiva y autónoma, cercana a la física y matemática, dio paso a una geografía nacionalista y subsidiaria de la Historia, para fortalecer la identidad y el ideal patrio chileno, toda vez que la república, a inicios del siglo XX ya se consolidaba. Así, el objetivo de la educación geográfica se alejó del ideal ilustrado, para iniciar un duradero matrimonio con el positivismo. Tal como plantea Soto (2000), la finalidad de la educación en general del período era "dar a la Patria ciudadanos que la defiendan, la dirijan, la hagan florecer y le den honor". La promulgación de la Ley de Instrucción Primaria Obligatoria de 1925 y del Decreto Fuerza de Ley N 5291 de 19299, reforzaron entonces los cambios y el modelo teórico que desde 1860 se venía movilizando. Tal como se pude ver en su artículo $\mathrm{N}^{\circ} 16$ :

9 República de Chile, Ministerio de Instrucción Pública: Ley No 3654 del 26 de Agosto de 1920. Conocida como Ley de instrucción Primaria Obligatoria y, ajustada por el Decreto Fuerza de Ley No 5291 de 1929, el cual fijó su texto definitivo. 
"La educación tiene como finalidad la formación física, moral e intelectual del niño (...) Para ello se trabajará la lectura y escritura, idioma patrio, doctrina y moral cristiana, higiene, ejercicios gimnásticos y militares y canto; dibujo lineal, geométrico de ornamentación y modelaje; trabajos manuales para los hombres y de agujas para las mujeres; cálculo, sistema métrico y nociones elementales de aritmética; geografía e historia patria, y nociones elementales de historia y geografía generales, especialmente geografía comercial e industrial" (Ministerio de Instrucción Pública, 1929:3)

Este cambio teórico, se sustentó básicamente en la influencia de los profesores alemanes llegados a Chile a fines del siglo XIX, quienes especialmente sustentados en la pedagogía herbartiana, introdujeron un nuevo concepto didáctico, otorgando una base científica y esencialmente psicológica al quehacer docente. Del mismo modo, para la Geografía se incorporaron los postulados de Humboldt y Ratzel, padres de la Geografía científica o moderna, y cuyo énfasis está en el espacio, acorde con el referente nacionalista del momento. Esta Geografía de corte positivista, cuyos contenidos son largas y exhaustivas descripciones del territorio nacional, divididas de forma analítica en el sentido de un escaparate, tanto en términos físicos como humanos, se mantuvo en Chile prácticamente sin modificaciones profundas hasta la reforma curricular de 1996.

La reforma curricular de 194910, reflejada en los planes y programas de estudio de 1953, además de estructurar contenidos, actividades y rendimientos, algo antes nunca visto en el currículum nacional, no implicó grandes transformaciones teóricas en la Geografía escolar y sus funciones. Según estos planes y programas, la Geografía siguió en hermandad con la Historia, tanto para la educación primaria como secundaria. Esto, a pesar de que ambas disciplinas fueron incorporadas junto a Educación Cívica, en la asignatura denominada Ciencias Sociales. Este cambio de nomenclatura no fue más que eso, ya que los objetivos y contenidos de la enseñanza siguieron centrándose en lo ya establecido en la ley de 1860 y en el plan de estudios concéntricos de 188911.

Más tarde, y a pesar de que sería esperable encontrar cambios importantes tras la Reforma Educativa de 196512 impulsada por el presidente Eduardo Frei Montalva, y que modificó la estructura del sistema educativo, transformando la educación primaria en educación general básica, y la formación en humanidades en educación media, previa a la educación superior, no hubo cambios teóricos profundos para la Geografía. Estos se dieron más a nivel metodológico y procedimental que de contenidos. Aún así, vale la pena destacar el aumento en el énfasis que a partir de esta reforma, se le da a la Geografía comercial e industrial, pero que será rápidamente diezmado con las transformaciones curriculares llevadas a cabo por el Gobierno Militar desde 1973. La reforma educativa de 1965, era una reforma del sistema escolar más que del currículum en un sentido disciplinar estricto, tal como plantea Brunner (1980:2)

"La Reforma debe dar a luz un nuevo orden en los albores de un tiempo que viene definido, básicamente, por la modernización y la incorporación de las masas y los grupos subalternos en la democracia. Debe conservar lo mejor del pasado, el orden social construido a lo largo de su historia

10 República de Chile, Ministerio de Educación Pública (1949) Planes y Programas de Estudio para la educación Primaria.

11 Una revisión de la Ley de 1860, conocida como la "Primera Ley de Instrucción Primaria", así como del plan de estudios concéntricos se encuentra en, Labarca, A. (1948) Historia de la Enseñanza en Chile. Universitaria, Santiago de Chile.

12 República de Chile, Ministerio de Educación Pública, Decreto Fuerza de Ley No 27952 del 20 de diciembre de 1965. Modifica Sistema Educacional. 
por la sociedad, pero liquidar las formas culturales obsoletas".

Uno de los ejes de la Reforma Educativa de 1965 fue la transformación de las prácticas de enseñanza, a partir de lo cual se desarrollaron los Liceos Experimentales, en los cuales se proponían, implementaban y evaluaban estrategias de enseñanza más efectivas. Sin embargo, según Soto (2000:36) "el conocimiento de la metodología de la enseñanza de la historia y la geografía fue paupérrimo. Difícilmente se encuentra en las revistas educacionales trabajos sobre el tema (...) Muños Hermosilla escribió Metodología Especial de la Geografía, no se publicó nunca". Las transformaciones de tipo metodológico de la enseñanza de la Geografía durante este período se explican por los avances de la psicología, tanto conductista y luego constructivista, y sus influencias en el quehacer pedagógico. Entre estas perspectivas se puede mencionar la adopción de la perspectiva piagetiana de trabajar desde lo concreto a lo abstracto, enseñar desde la observación directa, y distinguir más entre fenómenos naturales y culturales. Estas son perspectivas que aún se evidencian en el currículum de Geografía, complementadas con las modificaciones realizadas por el gobierno militar (1973-1990) el cual desde una mirada esencialmente positivista, conductista, y con un objetivo eminentemente nacionalista, puntualizó:

“- Ha de capacitarse al niño para hacer discriminaciones sencillas entre los fenómenos naturales y los culturales, así como entre los que pertenecen al mundo mágico supersticioso y aquellos de la esfera de lo real.

- Corresponde dar una especial consideración al papel del niño en relación con su grupo familiar, escuela y nación.

- Los actos cívico culturales han de servir para reforzar estos valores nacionales y personales de gran significación formativa de modo que el niño pueda apreciar nuestro legado cultural" (Ministerio de Educación, 1974: 23)

Si bien la Historia y la Geografía, a partir de la Reforma de 1965 pasaron a ser parte del programa de ciencias sociales en primer y segundo ciclo de educación básica, sus contenidos siguieron siendo tratados desde una perspectiva aislada y naturalista. En términos de planeación, en primer ciclo de educación básica se partía con contenidos de Historia, para luego dar paso a Geografía, en la octava unidad, básicamente en dos grandes temáticas: "Chile, un rincón de nuestro planeta" y "Nuestro planeta la Tierra, nuestra estrella el Sol, una próxima conquista: la Luna" (Ministerio de Educación, 1970: 27-28) En segundo ciclo básico, se seguía la tendencia de partir con contenidos de Historia, y luego Geografía. En cuanto a contenidos, hay un esfuerzo por incluir al ser humano en la mirada geográfica, pero se mantiene la tradicional fragmentación positivista entre el mundo natural y cultural, y en cuanto a metodología, se parte desde lo cercano (barrio y ciudad) para avanzar hacia lo más lejano (región, país y el mundo).

Resulta necesario destacar que en este período, el enfoque curricular considera a las regiones como unidades naturales, y no en la perspectiva político administrativa actual. Esto se explica por el modelo positivista naturalista de la Geografía del período. En educación media, las Ciencias Sociales cambian de nombre en tercer y cuarto año medio, y se llamó Ciencias Sociales e Historia de Chile. En este nivel se observa un paradigma en tensión con el positivismo, respecto de las funciones y objetivos de la educación. Los planes y programas de estudio de Ciencias Sociales (1970) señalan: 
"Si consideramos que la educación más que una ciencia y una técnica es Humanismo, retorno al Hombre y a su dignidad inherente, debemos aceptar que la asignatura de Ciencias Sociales e Históricas es por su naturaleza, importancia formativa y riqueza conceptual, la que mayor aporte entrega a la formación del Hombre Integral" (Ministerio de Educación, 1970: 60)

Los contenidos de Geografía, a diferencia de la visto en educación básica, no se localizaban en términos curriculares, necesariamente al final del ciclo o nivel. Sin embargo la justificación de su posición curricular radica en la relevancia del espacio geográfico como escenario para comprender fenómenos históricos. Así, por ejemplo en primero medio, los contenidos de Geografía eran parte de la primera unidad, trabajando temáticas como la Tierra, naturaleza y el hombre en el mundo americano. Estos contenidos eran trabajados desde una mirada temporal y no espacial, ya que se constituían como marco para el estudio de temas posteriores como culturas americanas, cultura europea, sociedad colonial y sociedad chilena. En segundo y tercero medio, sólo se trabajaban contenidos históricos y la Geografía no es más que un escenario para dichos contenidos. En cuatro año medio, la Geografía reaparece, fragmentada de la historia aunque igualmente subsidiaria, dividida en tres unidades: "La población, características y problemas actuales", La gran ciudad, medio ambiente óptimo y problemático" y "Geografía Regional de Chile" (Ministerio de Educación, 1970: 65).

Con el inicio del Gobierno Militar en 1973, el currículum, los planes y programas de estudio que, según la planificación de la Reforma de 1965 debían estar listos en 1974, se vieron nuevamente modificados. Los equipos dispuestos por el gobierno militar emprendieron las transformaciones de los programas, con especial ahínco en el primer ciclo de educación básica y en cuarto medio, momentos claves desde una perspectiva formativa, para inculcar el espíritu nacionalista y patriótico, como se plantea en los Planes y Programas de Estudio de la Educación General Básica:

"Las sugerencias y modificaciones que se han introducido a los contenidos programáticos de Ciencias Sociales de Primero a Cuarto año de Educación Básica, han estado inspiradas en las nuevas orientaciones de la política educacional, tendientes a dar un mayor énfasis a los valores nacionales" (Ministerio de Educación, 1975: 23)

El currículum naciente de la Reforma de 1965, buscaba crear un compromiso ético con la modernidad, y propiciar la integración y el desarrollo social. Por el contrario, el currículum de 1975 buscaba una educación diferenciadora (Brunner, 1980) lo que se vio consolidado con la Reforma educativa y curricular implementada en 1980:

Los hombres, "llamados a ser buenos trabajadores, ciudadanos y patriotas, determinan la meta mínima y primordial de la enseñanza básica. Cuál es, que los egresados de ella: sepan hablar, leer y escribir correctamente el idioma patrio; dominen las cuatro operaciones aritméticas y sus nociones complementarias esenciales; conozcan sistemática y cronológicamente, en el nivel de profundidad que corresponda a este nivel de instrucción, la Historia de Chile y conozcan también su geografía" (Directiva Educacional, 1979: 5)

De este modo, el curriculum escolar fue orientado de acuerdo a sus nuevos objetivos. Así, en primer y segundo ciclo básico se privilegiaba el aprendizaje de un conjunto de contenidos en cuatro disciplinas muy específcas: Matemática, Castellano, Historia y Geografia. En concordancia con los principios de descentralización, el principio fundante del cambio curricular, según Cox (2003), fue la flexibilización de la regulación estatal, más que una propuesta sobre los saberes a tratar por un sistema escolar contemporáneo. Con la Reforma de 1980 la Geografia escolar recibe en su máximo esplendor al positivismo y al ideario nacional como ejes centrales. Así, a 
partir del Decreto Fuerza de Ley 4002 de 198013, la educación básica tiene entre sus objetivos:

"Desarrollar su sentido patrio y conocer la historia y geografía de Chile con la profundidad que corresponde a este nivel. Así como conocer las nociones elementales de las Ciencias Naturales y Sociales; comprender y valorar la importancia del medioambiente" (Ministerio de Educación, 1980: $1-2)$

Para ello, la educación básica, de ocho años de duración, se organizaba en asignaturas y actividades de formación. La Geografía continuó unida a la Historia, en un área definida como Área de Experiencia, junto a Ciencias Naturales y Religión. Durante el primer ciclo era parte de la asignatura llamada Sociedad, Geografía e Historia; de quinto a séptimo año básico, Historia y Geografía, y en octavo básico se denominaba Historia, Geografía y Ciencias Sociales (Ministerio de Educación, 1980).

Durante el primer ciclo, la Geografía buscaba que los estudiantes conocieran los rasgos más relevantes del territorio, y los contenidos geográficos son poco abundantes, pero densos. Se da especial importancia a los sistemas de ubicación y diferenciación de la posición de Chile frente a otros países del mundo. En segundo ciclo, desde una lógica deductiva, se incorpora el sistema solar y la fisonomía geográfica de Chile, así como localización y rasgos geográficos generales, considerando especialmente actividades económicas. En sexto básico, el eje geográfico se centra en Europa, particularmente en el Mar Mediterráneo. A pesar de su fuerte orientación política e ideológica, la Geografía escolar de esta etapa, sigue incorporando en sus contenidos, paisajes y características geográficas que si bien no son típicas de Chile, permiten diferenciar y determinar su magnificencia territorial. Esto hace que se incluyan contenidos de difícil comprensión en educación básica, como la expansión territorial de Chile, en octavo año.

Por último, la educación media, de cuatro años de duración, también se organizó en asignaturas y actividades formativas. El Decreto Fuerza de Ley No 332 de 198114, muestra entre los objetivos de la educación media:

"Desarrollar la capacidad para comprender y participar de los cambios físicos y culturales que ocurren en el mundo. Conocer y apreciar el medio natural como un ambiente dinámico para el desarrollo de la vida humana" (Ministerio de Educación, 1982: 1)

Durante el primer ciclo de educación media, la Geografía era parte de la asignatura llamada Historia Universal y Geografía General, con cinco horas pedagógicas semanales. En segundo ciclo se incorporaba dentro de Historia y Geografía de Chile, con tres horas pedagógicas semanales. Tanto en primer como en segundo ciclo, la perspectiva para trabajar los contenidos era regional. En primer ciclo, los contenidos se podrían resumir en lo que se denomina Geografía regional del mundo, y en segundo ciclo se podrían conceptualizar como geografía regional de Chile. En este currículum se incorpora una mirada naturalista de las regiones, pero el énfasis está en la división político administrativa que se instauró en 1974.

13 República de Chile, Ministerio de Educación, Decreto Fuerza de Ley 4002 del 20 de mayo de 1980 Fija Objetivos, Planes y Programas de la Educación General Básica.

14 República de Chile, Ministerio de Educación Pública. Decreto Fuerza de Ley No 332 del 30 de diciembre de 1981. Aprueba Planes y Programas para la Educación Media Humanístico-Científica. 
La planeación de las unidades didácticas en educación media, con un enfoque analítico, consideraba a la Geografía luego de vistos los contenidos de Historia. Dado lo extenso de la programación, esto generaba que los contenidos no fueran trabajados por falta de tiempo, o fueran vistos superficialmente, en una perspectiva tradicional y memorística que atentaba contra el aprendizaje. Así, a pesar de las reformas educativas durante el siglo XX en nuestro país $(1920,1943,1965,1982)$ la Geografía no se vio influenciada ni por orientaciones pedagógicas experimentales, ni por avances teóricos.

En 1970, cuando se implementa la reforma curricular de 1965, la Geografía escolar descansa sobre un modelo positivista de tipo sociológico, cuando la Geografía mundial avanza sobre el modelo neopositivista de la Nueva Geografía de corte estadístico y economicista, con los aportes de Hagerstrand, Cristhaller y Ullman. Del mismo modo en 1980, cuando la Geografía escolar chilena vuelve a su más férreo referente de nacionalismo patriótico y positivismo ratzeliano, la Geografía mundial avanza hacia perspectivas fenomenológicas con los aportes de Lowenthal, Tuan, Massey y Buttimer, así como en la corriente crítica de Milton Santos.

\begin{tabular}{|c|c|c|c|c|c|c|}
\hline$\underline{\text { Período }}$ & Extensión & $\begin{array}{l}\text { Posición } \\
\text { curricular }\end{array}$ & 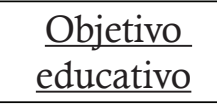 & $\begin{array}{l}\text { Contenidos } \\
\text { disciplinares }\end{array}$ & $\frac{\text { Disciplinas }}{\underline{\text { afines }}}$ & $\begin{array}{c}\text { Modelo } \\
\text { epistemológico }\end{array}$ \\
\hline $\begin{array}{l}\text { Geografía } \\
\text { subsidiaria }\end{array}$ & $\begin{array}{l}\text { Desde la } \\
\text { unión de la } \\
\text { geografía y } \\
\text { la historia } \\
\text { como } \\
\text { asignatura } \\
\text { del plan de } \\
\text { estudios } \\
\text { concéntricos } \\
\text { (1889) hasta } \\
\text { la Reforma } \\
\text { curricular de } \\
1996\end{array}$ & $\begin{array}{l}\text { Nivel } \\
\text { primario. }\end{array}$ & $\begin{array}{l}\text { Valorar la } \\
\text { geografía } \\
\text { nacional, } \\
\text { promoviendo } \\
\text { la formación } \\
\text { de la } \\
\text { identidad y el } \\
\text { ideal patrio }\end{array}$ & $\begin{array}{l}\text { Geografía } \\
\text { Regional del } \\
\text { Mundo. } \\
\text { Geografía } \\
\text { Regional de } \\
\text { Chile. } \\
\\
\text { Hitos de la } \\
\text { geografía } \\
\text { local, } \\
\text { regional y } \\
\text { nacional. }\end{array}$ & $\begin{array}{l}\text { Historia y } \\
\text { Educación } \\
\text { cívica. }\end{array}$ & $\begin{array}{l}\text { Geografía } \\
\text { positivista }\end{array}$ \\
\hline
\end{tabular}

Figura $\mathrm{N}^{\circ}$ 2: Características de la geografía escolar durante el siglo $\mathrm{XX}$ Fuente: Elaboración propia

Lo anterior hace pensar que los cambios de la Geografía escolar, cuando efectivamente los hubo durante el siglo XX, se explicaron más por sus relaciones con la conformación y consolidación del Estado nación, que con los avances teóricos y metodológicos de la disciplina. La Geografía académica entonces, desde su origen buscó diferenciarse de la Geografía escolar y la que se trabajaba a nivel del profesorado. Los estudios de geografía fueron parte de la formación del profesorado desde 1889, al crearse el Instituto Pedagógico de la Universidad de Chile. Sin embargo, la institucionalización de la Licenciatura en Geografía no llegó hasta 1970, tanto en la Universidad de Chile como en la Universidad Católica (Santis, 1990). Esto significa que los estudios geográficos en Chile fueron por más de un siglo, estudios pedagógicos considerados menos científicos que los que la Geografía académica necesitaba: 
"Entre 1959 y 1964 se desarrolló el seminario de estudios geográficos que constituyó un grupo de reflexión en torno a la geografía como disciplina científica (...) La preocupación se centraba en superar el estadio de un saber condicionado a la formación didáctica e inexplicablemente ligado a la historia, fundado en una aproximación naturalista y, en la descripción razonada de la región" (Santis, 1990: 7).

Esta mirada neopositivista de la Geografía, influenciada por autores como Hagerstransd y Harvey fue la que impulsó la escisión entre Geografía escolar y académica, y cuyos resultados se ven hoy, especialmente respecto de la articulación entre Geografía de nivel medio y de nivel superior o universitario, diferencias evidenciadas mayormente en el ámbito de la investigación. Así, la Geografía escolar durante la mayor parte del siglo XX, experimentó inmovilismo y estancamiento teórico, a pesar de los avances que la Geografía académica mostraba. Este inmovilismo, característico de la mayor parte de las disciplinas del currículum durante el siglo, así como las necesidades de nuevos referentes teóricos, estimularon a los gobiernos democráticos de la década de 1990 a impulsar un proceso de reforma educativa que por una parte, modificara los patrones impuestos por el gobierno militar, que no coincidían con las necesidades de una convivencia democrática, y que promoviera un cambio en los objetivos y contenidos de las disciplinas curriculares. De esta forma, la reforma curricular acaecida entre 1996 y 2002, produjo cambios interesantes en la educación en general, y cambios teóricos profundos a la educación geográfica en particular.

La educación geográfica en el siglo XXI: La geografía como disciplina integrada a los estudios sociales.

Ya en 1973, Schwab señalaba: "De los cuatro tópicos de la educación -el educando, el educador, el medio y la asignatura- ninguno ha sido tan ampliamente descuidado como el último, durante el medio siglo pasado" (Schwab, 1973: 25).

De acuerdo a lo anterior, el estancamiento teórico de la Geografía escolar durante el siglo XX es una generalidad del currículum. Si bien se pueden observar al menos tres grandes reformas relevantes $(1920,1965,1980)$, ellas tuvieron su énfasis en el sistema escolar, su estructura y organización, pero los contenidos de enseñanza fueron poco modificados. Este fenómeno, según Nervi (2003) resulta una paradoja, ya que el siglo XX se caracterizó por la arremetida del saber, mientras que el pensamiento educativo y curricular, otorgó poco espacio al estudio sobre los desarrollos del conocimiento fuera de la escuela, promoviendo una excesiva psicologización de los procesos de enseñanza-aprendizaje, y una práctica pedagógica rutinaria (Flórez, 1994)

Para el caso de la Geografía, esta tendencia se vio acentuada por la consolidación y endurecimiento de la perspectiva positivista impulsada por el currículum del Gobierno Militar, y por la bifurcación establecida en 1970 entre la Geografía escolar y la académica, lo que atentó no sólo contra las prácticas de enseñanza efectivas, sino también contra el proceso de aprendizaje significativo. Factores como estos, además de los bajos resultados académicos y, las necesidades de promover un nuevo tipo de ciudadanía, acorde a los nuevos tiempos, caracterizados por la democracia y la globalización, incentivaron a partir de 1996 un nuevo proceso de reforma educacional, la cual bajo la premisa de calidad y equidad, inició profundas transformaciones al sistema escolar, pero especialmente a su nivel curricular. 
Si bien el nuevo currículum, dadas las exigencias de flexibilidad y descentralización contenidas en la Ley Orgánica Constitucional de Educación (LOCE) promulgada por el Gobierno Militar en 1990 tuvo que mantener dichos principios, se realizaron cambios de estructura y contenidos. En primer lugar se diferenció el marco curricular a través de un Decreto Fuerza de Ley, obligatorio para todos los establecimientos del país, de los tradicionales planes y programas conocidos hasta el momento y que desde ese momento tuvieron carácter optativo, pudiendo los establecimientos, elaborar sus propios planes y programas dependiendo de sus necesidades. Así el nuevo marco curricular quedó formulado en términos de Objetivos Fundamentales, transversales y, verticales (OFT y OFV, respectivamente) y Contenidos Mínimos Obligatorios (CMO)15. Como plantea Cox $(2006,11)$

"Fueron definidos articulando las distinciones entre contenidos conceptuales y habilidades. Define asimismo Objetivos Transversales en términos de valores, habilidades, y actitudes, sin explicitar qué temas emergentes son de incumbencia de esta nueva área. Junto con estos cambios, los OF-CMO procuran actualizar el conocimiento así como orientar el conjunto hacia la práctica educativa centrada en la actividad de los alumnos".

Por su parte, las actividades y rendimientos esperados, tradicionalmente incluidos en el currículum nacional, ahora eran parte de planes y programas optativos. El núcleo del cambio curricular fue una reorientación de los objetivos y contenidos dentro de cada asignatura, y el propósito orientador fue dotar a los estudiantes de herramientas intelectuales que los habilitaran para su vida en el siglo XXI (Cox, 2006).

Esto significó la necesidad de incorporar un nuevo eje transversal de habilidades y actitudes relacionadas con la democracia y derechos humanos, en sustitución a la tradicional educación cívica. Con el nuevo marco curricular, la Geografía desapareció en términos nominativos y los estudios sociales fueron modificados y replanteados. En el caso del primer ciclo de educación básica, se creó un nuevo sector de aprendizaje, integrado e interdisciplinario, denominado Estudio del medio natural, social y cultural, que agrupaba los contenidos de Ciencias Sociales y Ciencias Naturales. En segundo ciclo básico se creó la asignatura denominada Estudio y comprensión de la sociedad, y en educación media, se cambió la denominación de Historia y Geografía por la de Historia y ciencias sociales (MINEDUC, 2002). El objetivo de estas acciones, como lo plantea Gysling (2003) era "hacer de esta área un área relevante para la vida del estudiante y, en ese sentido, cobró mucha fuerza la intención de proveerla de una visión de la sociedad donde más que enseñarles Historia, Geografía o Ciencias Sociales, lo importante era ofrecer una visión estructurada de la realidad social" (Nervi, 2003: 64)

Esta desaparición de la Geografía en el nombre de la asignatura no fue sólo nominativa, sino que implicó el recorte y disminución sustantiva de los contenidos a enseñar y de habilidades a desarrollar, así como la reorganización de estas, en nuevos núcleos de aprendizaje. La Geografía fue invisibilizada e integrada al conjunto de las ciencias sociales, lo que resultaba más acorde con el modelo epistemológico dominante para la Geografía contemporánea, vale decir, la teoría crítica. Sin embargo, este sustento de carácter epistemológico para la denominación del sector de aprendizaje,

15 República de Chile, Ministerio de Educación. Decreto Supremo de Educación No 232 de 2002. Fija Marco Curricular para la Educación General Básica.

República de Chile, Ministerio de Educación. Decreto Supremo de Educación No 220 de 2002. Fija Marco Curricular para la Educación Media. 
no se materializó en la explicitación de contenidos, y mucho menos en las prácticas de enseñanza, ya que la mayoría de los profesores en ejercicio durante la primera etapa de la implementación de le Reforma curricular, habían sido formados bajo el modelo positivista y naturalista, contradictorio con los nuevos postulados:

"Los geógrafos han dicho que se dio relevancia a la historia y a ellos se les invisibilizó, incluyéndolos en el conjunto de las Ciencias Sociales (...) En la propuesta curricular esto no sólo constituye una nominación disciplinaria, sino que en realidad implica destacar que este currículo contiene fuerte presencia de la Historia y de Ciencias Sociales. Geografía está bastante integrada en función de la realidad social, no se trata de la geografía física tradicional, sino de un enfoque regional; más analítico, constituye otra manera de enfocar a la geografía y por ello no se perfiló una denominación explícita, porque no interesa hacer esa separación" (Gysling, 2003)

Según los elaboradores del currículum de entonces (Gysling, 2003), la Geografía ahora se desarrollaba desde una perspectiva regional, de lo propio a lo más lejano. "En Primer Año medio, toda la parte inicial de conocimiento de la Región puede ser vista desde la geografía regional, que es un enfoque que integra elementos, así por ejemplo, el tema de la diversidad cultural, propio de la antropología, está incluido dentro del análisis regional como una dimensión más (...) La otra alteración grande es que se parte desde lo propio a lo más lejano, se avanza desde la realidad y la historia más local hacia una historia universal y una visión más globalizada." (Nervi, 2003: 69).

Si bien, la apuesta puede ser interesante, en esta nueva concepción curricular de la Geografía se incurre en algunos desconocimientos de los currículos anteriores, frente a los cuales se pretende hacer una distinción y una separación. Gysling (2003) plantea que el nuevo currículum de 1996, otorga un "nuevo" enfoque regional, más analítico. Sin embargo, y como ya se planteó, el enfoque regional es una constante en el curriculum de Geografía chileno y se encuentra presente en prácticamente todo su desarrollo histórico, y con más fuerza luego de las Reformas de 1965 y de 1980. Del mismo modo, la perspectiva analítica fue incorporada a la Geografía escolar con la arremetida del positivismo a inicios del siglo XX, de modo tal que plantear que, el currículum elaborado en 1996 es el que presenta este enfoque, es una falacia.

Del mismo modo, si bien el trabajo interdisciplinario de las Ciencias Sociales en el ámbito escolar podría verse como una ventaja, esto tuvo poca aplicación en la práctica debido a que la formación de profesores se mantuvo en una perspectiva de especialización disciplinar y fragmentaria. Tal como plantea Goodson (1995) la reforma curricular preservó, a pesar de los cambios de nombres de las asignaturas, el tradicional formato disciplinar, manteniendo el orden general del conocimiento ilustrado típico de la modernidad (Nervi, 2003). Respecto a los contenidos de Geografía, muchos de ellos desaparecieron, dando más relevancia al conocimiento de la localidad y la región, aunque se mantuvo la escisión entre aspectos naturales y culturales, anulando al ser humano, componente fundamental del espacio geográfico. Se incorporaron también algunos contenidos procedimentales como cartografía temática y topográfica, uso de planos y estadísticas geográficas para geografía de la población.

Otro aspecto novedoso, según la Unidad de Currículum y Evaluación del Ministerio de Educación (2002) era la perspectiva de trabajo lineal que va desde lo cercano a lo lejano, y de lo concreto a lo abstracto. Este enfoque encuentra sus sustentos en la teoría de Piaget, sin embargo, no se puede decir que resultaba novedosa en 1996, cuando ya había sido incorporada al currículum de 1965. 
Además, esta perspectiva se encontraba desactualizada de los avances didácticos de la geografía, que venían demostrando que los estudiantes pueden transitar por diversas escalas de análisis, dando múltiples y simultáneos saltos entre ellas, y que no necesariamente el aprendizaje de la geografía ocurre de un modo lineal, como se promovía con dicho currículum.

Al igual que para la educación básica, en educación media la finalidad de esta área del conocimiento era "desarrollar en los estudiantes conocimientos, habilidades y disposiciones que les permitan estructurar una comprensión del entorno social y les orienten a actuar crítica y responsablemente en la sociedad, sobre la base de principios de solidaridad, cuidado del medio ambiente, pluralismo y, valoración de la democracia y de la identidad nacional" (Ministerio de Educación, 2002)

Sin embargo, las modificaciones para la Geografía fueron mucho más profundas en la educación media, y los contenidos de Geografía, repartidos en cuatro años de enseñanza, fueron reducidos y comprimidos al punto de concentrarlos sólo el nivel primero medio. Esto, se podría haber justificado por la mirada interdisciplinaria de las Ciencias Sociales, sin embargo, la mirada predominante del currículum, tanto para la Geografía como para las demás Ciencias Sociales fue la perspectiva analítica, fragmentaria y disciplinar. Aún cuando el sector era denominado Historia y Ciencias Sociales, era posible identificar con mucha claridad, los contenidos de cada una de las disciplinas sociales, sin detectar una real integración.

Aproximadamente la mitad de los contenidos de primero medio correspondían a contenidos geográficos, pero estos se articulaban escasamente con los contenidos de educación básica, y nulamente con los de las demás etapas de la educación media, por lo que en vez de ser un aporte para la comprensión de la sociedad, se constituían como una isla de aprendizaje, promovedora de prácticas educativas rutinarias y memorísticas, con poco impacto en la vida de los estudiantes. Estos contenidos eran trabajados en dos núcleos de aprendizaje: uno denominado "Entorno natural y comunidad regional", que analizaba las características físicas, humanas y económicas de la región donde estaba inserto el establecimiento educacional, así como sus principales problemas ambientales, y las expresiones de diversidad cultural. Y otro núcleo denominado "Organización Regional" que analizaba el sistema urbano-rural, redes de comunicación de la región, territorio, su ordenamiento y planificación, y la división político-administrativa del territorio tricontinental (Ministerio de Educación, 2002)

Como se puede observar, lo que antes de la Reforma curricular era trabajado en dos años, luego de ella debía ser trabajado sólo en un semestre. Esta compresión atentó profundamente contra el espíritu de la reforma en el área, por cuanto intensificó las estrategias de enseñanza a modo de inventario, y el aprendizaje memorístico. Si bien, es posible visualizar algunos temas geográficos en los otros niveles, especialmente en tercero y cuarto año medio, estos no rompieron con la tradicional consideración del espacio geográfico a modo de escenario de los procesos históricos y sociales. Esto significó que los grandes cambios realizados con el objetivo de mejorar la enseñanza de la Geografía no pasaran de una declaración de buenas intenciones.

Ahora bien, tras casi catorce años de Reforma educacional y curricular, entre los años 2009 y 2010 hemos sido testigos de un proceso de actualización del currículum, sustentado en el rápido avance del conocimiento y la información durante la última década. Dicho proceso de actualización corresponde a un proceso de ajuste del currículum, y no a una nueva reforma curricular. En general, las finalidades de las disciplinas curriculares se mantienen, así como el grueso de los contenidos. Sin 
embargo, luego de más de 10 años de evidencias sobre los resultados del nuevo currículum, este ha sido ajustado según las nuevas necesidades.

En el caso de la geografía, esta recuperó su posición en el nombre del subsector desde primero básico. El subsector, Estudio del medio natural, social y cultural, fue eliminado para volver a la tradicional separación de las ciencias naturales y las ciencias sociales en subsectores o asignaturas distintas. El subsector, desde primero básico a cuarto año medio, es denominado Historia, Geografía y Ciencias Sociales, y si bien, con el ajuste curricular la Geografía continua en el ámbito de las ciencias sociales, ha recuperado su identidad y su fuerza disciplinar. Las habilidades de pensamiento geográfico por primera vez se han hecho explícitas y se han relevado dentro del grupo de las habilidades de pensamiento social.

"Este sector también se propone que los estudiantes desarrollen el pensamiento espacial, con una visión dinámica y sistémica, que les permita comprender el territorio como una construcción humana posible de modificar en beneficio de la calidad de vida de las personas que lo habitan" (Ministerio de Educación, 2010: 195)

Otro aspecto de cambio para la educación geográfica, es la incorporación del principio de dificultad creciente que organiza los contenidos desde las habilidades más sencillas a las más complejas de desarrollar en el proceso de aprendizaje, y no desde lo concreto a lo abstracto o de lo cercano a lo lejano como se había realizado hasta ahora:

"Para hacer frente a la amplitud temática del sector, y considerando la reciente legislación que hace obligatoria la enseñanza escolar hasta cuarto medio (...) y el mayor caudal de información al que acceden los jóvenes a través de los medios de comunicación y de la tecnología, en este currículum se ha replanteado la relación concéntrica entre la enseñanza básica y la enseñanza media, insistiendo en la progresión continua del aprendizaje" (Ministerio de Educación, 2010: 197)

Del mismo modo, los contenidos se agrupan en tres dimensiones, progresivas a lo largo de todo el proceso escolar: Localización espacial y comprensión sistémica del espacio geográfico; habilidades de análisis territorial, y habilidades y actitudes de valoración y actuación responsable con el espacio (Ministerio de Educación, 2009)

"Las habilidades geográficas tienen como propósito desarrollar en alumnos y alumnas la ubicación espacial y el análisis territorial, en el cual han de poder integrar diversas variables para adquirir una visión dinámica y sistémica del espacio que habitan. Las habilidades de ubicación espacial progresan desde primero a quinto básico, en relación a la ubicación y distribución de procesos naturales y sociales. Las habilidades de análisis territorial progresan desde sexto básico hasta cuarto medio, y con ellas se busca que los estudiantes logren integrar variables para explicar la dinámica espacial de distintos procesos en un territorio hasta llegar a una visión sistémica del espacio que habitan, lo que les permitirá comprender que el territorio es una construcción humana y posible de modificar en beneficio de la calidad de vida, contribuyendo de esta manera a la formación de ciudadanos capaces de evaluar las implicancias que tiene el desarrollo sustentable para su vida y la de la humanidad" (Ministerio de Educación, 2010: 197).

Así entonces, la Geografía vuelve a estar presente en todos los niveles, aunque con más fuerza en unos que en otros. Conviene destacar también que en el ajuste curricular, la Geografía escolar recupera al ser humano como eje estructurante, y desde la mirada sistémica se acerca a enfoques teóricos que hoy se posicionan con fuerza en la Geografía académica. 


\begin{tabular}{|c|c|c|c|c|c|c|}
\hline$\underline{\text { Período }}$ & Extensión & $\begin{array}{l}\text { Posición } \\
\text { curricular } \\
\end{array}$ & $\begin{array}{r}\text { Objetivo } \\
\text { educativo } \\
\end{array}$ & $\begin{array}{r}\text { Contenidos } \\
\text { disciplinares } \\
\end{array}$ & $\begin{array}{c}\frac{\text { Disciplinas }}{\text { afines }} \\
\end{array}$ & $\begin{array}{c}\text { Modelo } \\
\text { epistemológico }\end{array}$ \\
\hline $\begin{array}{l}\text { Geografía } \\
\text { integrada }\end{array}$ & $\begin{array}{l}\text { Desde } \\
\text { reforma } \\
\text { curricular de } \\
1996 \text { hasta } \\
\text { los ajustes } \\
\text { curriculares } \\
\text { de } 2010\end{array}$ & $\begin{array}{l}\text { Nivel } \\
\text { primario }\end{array}$ & $\begin{array}{l}\text { Desarrollar } \\
\text { habilidades de } \\
\text { pensamiento } \\
\text { espacial que } \\
\text { permitan la } \\
\text { comprensión } \\
\text { de la } \\
\text { sociedad y la } \\
\text { participación } \\
\text { ciudadana }\end{array}$ & $\begin{array}{l}\text {-Localización } \\
\text { espacial y } \\
\text { organización } \\
\text { sistémica del } \\
\text { espacio geográfico. } \\
\text {-Análisis } \\
\text { territorial. } \\
\text {-Vinculaciones } \\
\text { entre espacio } \\
\text { geográfico } \\
\text { y desarrollo } \\
\text { sustentable. }\end{array}$ & $\begin{array}{l}\text { Historia y } \\
\text { Ciencias } \\
\text { Sociales }\end{array}$ & $\begin{array}{l}\text { Geografía } \\
\text { sistémica. }\end{array}$ \\
\hline
\end{tabular}

Figura $\mathrm{N}^{\circ}$ 3: Características de la geografía escolar durante el siglo XX Fuente: Elaboración propia.

El ajuste curricular significa un gran avance teórico y pedagógico para la Geografía. Al recuperar su identidad, la Geografía avanza en el trabajo interdisciplinar a lo largo de toda la escolaridad, y su relación con la Historia deja de ser subsidiaria, para ser complementarias, al igual que con las demás Ciencias Sociales.16 Sin embargo, y dado lo reciente de la publicación de los ajustes y su lenta implementación en las escuelas del país, aún no es posible ver los resultados de los cambios curriculares. Aún así, se espera que los avances teóricos a nivel curricular, potencien nuevas prácticas de enseñanza y aprendizaje de la Geografía, de modo de intensificar el sentido y finalidad social que esta disciplinar curricular tiene, que es ayudar a la comprensión de la sociedad desde una dimensión espacial y promover la acción ciudadana.

\section{CONSIDERACIONES FINALES}

Habiendo analizado los diversos currículum escolares en que ha estado presente la Geografía, es posible plantear que la disciplina es parte del currículum formal desde el inicio del sistema educativo. Su presencia se ha sustentado desde distintas perspectivas teóricas según los momentos históricos y las orientaciones epistemológicas imperantes. Así, en el devenir de la Geografía escolar se visualizan tres momentos:

Un primer momento, desde fines de la colonia hasta inicios del siglo XX, en que la Geografía escolar es una disciplina autónoma, muy relacionada con la matemática y física, que puede ser catalogada como pre científica o pre moderna. Es un período en el que la Geografía escolar se diferencia poco de la Geografía académica, cuyo fin era la descripción de la superficie terrestre.

16 También, el subsector de Historia, Geografía y Ciencias Sociales, a lo largo de su secuencia, resguarda diversas relaciones con otros sectores de aprendizaje contemplados en el currículum nacional, y se presentan múltiples posibilidades para realizar un trabajo pedagógico de integración con los otros sectores curriculares (Ministerio de Educación, 2010) 
Un segundo momento, que va desde inicios del siglo XX hasta 1990, en que la Geografía se vuelve una disciplina escolar subsidiaria de la Historia. En este período la Geografía es incorporada a la educación primaria, desde los primeros niveles, dada su relevancia para la consolidación de la identidad nacional. El sustento epistemológico de base es el positivismo y en algunos casos el naturalismo, paradigma que dominará el currículum escolar de Geografía durante prácticamente todo el siglo XX.

Un tercer momento, desde 2000 hasta la actualidad, donde la Geografía escolar es entendida como una disciplina integrada, bajo un modelo preferentemente sistémico que avanza en el diálogo y la polifonía de las ciencias sociales, aunque sigue su lucha con las herencias del período anterior.

Desde esta perspectiva, la Geografía escolar chilena, actualmente permite ser trabajada desde una perspectiva integradora, lo que brinda amplias posibilidades de aprendizaje. Del mismo modo, el desarrollo histórico de la Geografía escolar mirado a través de su currículum, nos dice que la Geografía ha presentado avances en la escuela, como se observa en los actuales ajustes curriculares, y también retrocesos teóricos y prácticos, como en el caso de la Geografía promovida por el Gobierno Militar y la presentada por los Gobiernos Democráticos de la década de 1990. Sin embargo, es posible plantear que los grandes cambios que se han observado en esta área del currículum se explican casi de forma exclusiva por sus íntimas relaciones con la figura del Estado nación y con ello, la relevancia de su impronta en la formación de los ciudadanos.

En conclusión, las modificaciones al currículum de Geografía se explican por la conformación de la identidad de los ciudadanos, más que por los avances teóricos y metodológicos de la Geografía misma como ciencia. Mientras las diferenciaciones y alejamientos entre la Geografía escolar y la Geografía académica universitaria no superen las bifurcaciones iniciadas en 1970 y, que fueron acentuadas con el paso del tiempo, a pesar de los esfuerzos que desde el currículum se realicen, no es esperable lograr mejoras sustantivas en la educación geográfica chilena.

\section{REFERENCIAS}

Acta de sociedad para la fundación de una universidad en Chile. El Señor Domingo Lambert, notario de París, 11 de abril de 1828.

Araya, F. y González, M. (2009) Presente y Futuro de la Educación Geográfica en Chile. Editorial Universidad de la Serena. La Serena, Chile.

Ávila, A. (1982) Mora y Bello en Chile (1829-1831). Ediciones de la Universidad de Chile, Santiago, Chile.

Barrenechea, E. (1913) Centenario del Instituto Nacional. Breve Reseña Histórica. Editorial Universitaria, Santiago, Chile.

Bazaguchiascúa, J. (1813) Memoria que manifiesta la necesidad de abrir grados e instituir cátedra de geografía en la Real Universidad de esta ciudad". Archivos varios, vol. No 276. Archivo Nacional. 
Brunner, J. (1980) Sociología de los principios educativos: Un análisis de las Reformas de los planes y programas de la enseñanza básica chilena, 1965-1980. FLACSO, Santiago, Chile.

Cox, C. (2003) Políticas Educacionales en el cambio de siglo. La reforma del sistema escolar de Chile. Editorial Universitaria, Santiago de Chile.

Cox, C. (2006) Construcción política de reformas curriculares: El caso de Chile en los noventa. En, Revista de Currículum y Formación del Profesorado, vol. 10, Nº 1, p. 1-24.

Flores, R. (1994) Hacia una pedagogía del conocimiento. Mc Graw Hill, Bogotá.

El Araucano, N 69, Santiago, 07 de enero de 1832.

E1 Mercurio Chileno, primer número. 12de marzo de 1828, p.34

El Mercurio Chileno, primer número, 12 de marzo de 1828, p. 35

El Mercurio de Valparaíso, Nº 33, del 17 de diciembre de 1828, pág. 129-130.

Godos, I. (1995) Historia del currículum. La construcción social de las disciplinas escolares. Pomares- Corredor, Barcelona.

Gysling J. (2003) "Reforma Curricular: Itinerario de una transformación cultural". En: Políticas educacionales en el cambio de siglo. La reforma del sistema escolar de Chile. Cristián Cox(editor), Editorial Universitaria, Santiago, Chile, pp. 213-252.

Labarca, A. (1948) Historia de la Enseñanza en Chile. Universitaria, Santiago de Chile.

Nervi, M. (2003) Los saberes de la Escuela. Análisis de la renovación disciplinaria en la reforma curricular 1996-2002. Editorial Universitaria, Santiago de Chile.

Pereira, E. (1947) Los comienzos de la enseñanza de la geografía en Chile. Editorial Universitaria, Santiago, Chile.

República de Chile, Ministerio de Educación Pública (1949) Planes y Programas de Estudio para la educación Primaria.

República de Chile, Ministerio de Educación Pública, Decreto Fuerza de Ley No 27952 del 20 de diciembre de 1965. Modifica Sistema Educacional.

República de Chile, Ministerio de Educación. Decreto Supremo de Educación No 232 de 2002. Fija Marco Curricular para la Educación General Básica. República de Chile, Ministerio de Educación. Decreto Supremo de Educación No 220 de 2002. Fija Marco Curricular para la Educación Media.

República de Chile, Ministerio de Instrucción Pública: Ley No 3654 del 26 de Agosto de 1920. Conocida como Ley de instrucción Primaria Obligatoria y, ajustada por el Decreto Fuerza de 
Ley $\mathrm{N}^{\circ} 5291$ de 1929, el cual fijó su texto definitivo.

Santis, H. (1981) Tradiciones en geografía: los modos del quehacer geográfico. En, Revista de Geografía Norte Grande. Vol. 8, p. 57-67.

Santis, H. (1990) El Instituto de Geografía de la Pontificia Universidad Católica de Chile. Sus primeros veinte años, 1970-1990. En, Revista de Geografía Norte Grande. Vol. 17. pp. 5-16.

Schwab, J. (1973) Problemas, tópicos y puntos en discusión, en Stanley, Elam (Comp.) La Educación y la Estructura del Conocimiento. El ateneo, Buenos Aires.

Soto, F. (2000) Historia de la Educación Chilena. Publicaciones CPEIP, Santiago, Chile. 